\title{
PREGNANCY OUTCOMES DO INFLUENCE BY EXTREMES OF BODY MASS INDEX
}

\author{
Lubna Razzak, Ramna Devi*, Sana Tariq, Anchal Seetlani**, Saira Jamshed* \\ Tabba Kidney Institute Karachi Pakistan, *Hamdard University Hospital Karachi Pakistan, **Zainab Panjwani Memorial Hospital Karachi Pakistan
}

\begin{abstract}
Objective: To investigate whether extreme of body mass index (BMI) is associated with pregnancy outcomes.

Study Design: Retrospective cohort study.

Place and Duration of Study: Hamdard University Hospital, Karachi, Pakistan, from Feb 2019 to Jan 2020.

Methodology: We conducted a retrospective cohort study of 1000 women delivered in between February 2019 to January 2020. $\mathrm{BMI}$ is categorized into four groups according to the Asian-Pacific cutoff points as underweight $\left(<18.5 \mathrm{~kg} / \mathrm{m}^{2}\right)$, normal weight $\left(18.5-22.9 \mathrm{~kg} / \mathrm{m}^{2}\right)$, overweight $\left(23-24.9 \mathrm{~kg} / \mathrm{m}^{2}\right)$, and obese $\left(>25 \mathrm{~kg} / \mathrm{m}^{2}\right)$. Maternal outcomes measured were pre-eclampsia, gestational diabetes, delivery by cesarean section, instrumental delivery, anemia, postpartum hemorrhage and fetal outcome included small for gestational age and large for gestational age. Logistic regression model was used to adjust the confounder. Maternal outcomes were evaluated with relative risks and $95 \%$ confidence intervals.

Results: In results, 13\%, 54\%, 22\%, 9\% and 2\% were underweight, normal body mass index, overweight, obese and morbidly obese categories respectively. The gestational diabetes, pre-eclampsia, labour induction, frequency of cesarean section, postpartum hemorrhage increased linearly with increasing body mass index and expressed as adjusted odds ratio (95\% confidence interval) respectively: 10.0 (95\% CI 3.5, 28.7), 5.3 (95\% CI 2.0, 14.1), 2.7 (95\% CI 1.1, 6.8), 4.9 (95\% CI 2.8-8.8), 2.5 (95\% CI 0.3120.6). The anemia and small for gestational age were found in underweight group with adjusted odd ratio2.47 (95\% CI $1.6-$ 3.6), 4.6 (95\% CI 2.6, 8.1) respectively.

Conclusion: Obese women are more prone to have maternal and fetal complication which includes preeclampsia, gestational diabetes, caesarean section rate, labor induction and macrosomic babies. Underweight women are not risk free for complication as they are associated with anemia and small for gestational age.
\end{abstract}

Keywords: Pregnancy outcome, Body mass index, Obesity, Large for gestational age.

This is an Open Access article distributed under the terms of the Creative Commons Attribution License (http://creativecommons.org/licenses/by/4.0), which permits unrestricted use, distribution, and reproduction in any medium, provided the original work is properly cited.

\section{INTRODUCTION}

The worldwide prevalence of obesity has been increasing and abnormal body mass index plays a major role to the attribution of chronic illness ${ }^{1}$. Obesity pondered to be major health burden not in developed but in underdeveloped countries ${ }^{2}$. According to population based survey the prevalence of obesity is increasing in female Pakistani population and itstrend has been increasing with advancing age ${ }^{3}$. It has been estimated that greater than one-third women aged 20 years and above in Pakistan are with abnormal body mass index 4 . According to survey, $26 \%$ of Pakistani women were classified as obese as compared to men who were $19 \%{ }^{4}$.

Body mass index (BMI) is considered to be an important gauge of pregnancy outcomes. Abnormal body mass index whether underweight or being obese may increase the risk of adverse pregnancy outcome. Various studies ${ }^{5,6}$ have shown that obesity contributed to occurrence of pregnancy complications such as gestational diabetes, pregnancy induced hypertension, post-

Correspondence: Dr Lubna Razzak, Consultant Gynecologist \& Urogynecologist, Tabba Kindney Institute Karachi Pakistan

Received: 04 Aug 2020; revised received: 31 Dec 2020; accepted: 05 Jan 2021 partum hemorrhage, macrosomia and stillbirth. Whereas pregnancy with underweight BMI, increased the risk of anemia and intrauterine growth retarda-tion? ${ }^{7}$.

Different studies have been done showing obesity with pregnancy outcome. There is paucity of data showing the effects of extreme of body mass index (BMI) on maternal and fetal outcomes. Therefore the objective of this study was to observe whether extremes of BMI (low or high) is linked with obstetric outcomes compared with women of normal BMI and to assess such risk in order to provide factual data for counseling women.

\section{METHODOLOGY}

A retrospective cohort study was conducted on 1000 singleton women delivered from February 2019 to January 2020. This study was approved by ethics review committee of department of Obstetrics and Gynaecology, Hamdrd University Hospital, Karachi. All pregnant women were enrolled in the study, who met the inclusion criteria. The inclusion criteria were singleton pregnancy, booked before 16 weeks of gestation and complete medical record available. The women with multiple pregnancies, booked after 16 weeks of gestation, incomplete medical record and medical 
condition like essential hypertension, diabetes mellitus and renal diseases were excluded from the study. The previous medical record was reviewed and information gathered in predesigned proforma. 1st trimester maternal height and weight was recorded and BMI was calculated.

BMI was calculated as weight in kilograms divided by the square of the height in meters $\left(\mathrm{kg} / \mathrm{m}^{2}\right)$. According to the Asian-Pacific cutoff points ${ }^{8}$, BMI was divided into four groups as underweight normal weight overweight and obese $\left(18.5 \mathrm{~kg} / \mathrm{m}^{2}\right),(18.5-22.9$ $\left.\mathrm{kg} / \mathrm{m}^{2}\right),\left(23-26.9 \mathrm{~kg} / \mathrm{m}^{2}\right)$, and $\left(>25 \mathrm{~kg} / \mathrm{m}^{2}\right)$ respectively. Maternal outcomes measured were pre-eclampsia, gestational diabetes, cesarean section rate, instrumental delivery, anemia, postpartum hemorrhage and fetal outcomes included small for gestational age and large for gestational age. The last menstrual period date was used to calculate the Gestational age and was confirmed by ultrasound. Multiple pregnancy, previous caesarean section and incomplete record were excluded from the study.
$55-60 \%$ women in obese and mobidly obese were nulliparous respectively whereas elderly age women (21-30\%) were more seen with overweight and obese women as compared to underweight or normal BMI groups (7-11\%).

According to BMI, the frequency of antenatal complications had beenpresented in (table-II). Table-III shows the complication of pregnancy risk expressed as odd ratio in the various categories of BMI in comparison with the normal BMI.

The gestational diabetes (GDM) and pre-eclampsia showed linear relationship with increasing BMI. The adjusted Odds Ratio in the morbidly obese category for gestational diabetes and pre eclampsia is 10.0 (95\% CI 3.5, 28.7) and 5.3 (95\% CI 2.0, 14.1) respectively compared to those of standard BMI. On the otherside BMI $>18.5 \mathrm{~kg} / \mathrm{m}^{2}$ has adjusted odd ratio $0.31(95 \% \mathrm{CI}$ $0.11,0.89)$ for pre-eclampsia and 0.18 (95\% CI 0.02, 1.3) for gestational diabetes, seemed to have a shielding effect for development of these complication of preeclampsia and GDM.

Table-I: Maternal demographic characteristics in the various body mass index groups.

\begin{tabular}{|c|c|c|c|c|c|}
\hline Variables & Underweight & Normal weight & Overweight & Obesity & Mobidly obese \\
\hline \multicolumn{6}{|l|}{ Age (years) } \\
\hline$<19$ & $10(8 \%)$ & $43(8 \%)$ & $05(33 \%)$ & $2(2.2 \%)$ & $1(5 \%)$ \\
\hline $20-25$ & $72(55 \%)$ & $254(47 \%)$ & $79(36 \%)$ & $33(37 \%)$ & $4(20 \%)$ \\
\hline $26-35$ & $39(30 \%)$ & $184(34 \%)$ & $97(44 \%)$ & $36(40 \%)$ & $9(45 \%)$ \\
\hline$>35$ & $9(7 \%)$ & $59(11 \%)$ & $39(18 \%)$ & $19(21 \%)$ & $6(30 \%)$ \\
\hline \multicolumn{6}{|l|}{ Parity } \\
\hline Nulliparous & $26(20 \%)$ & $183(34 \%)$ & $99(45 \%)$ & $49(55 \%)$ & $12(60 \%)$ \\
\hline $1-4$ & $75(58 \%)$ & $259(48 \%)$ & $105(48 \%)$ & $31(34 \%)$ & $7(35 \%)$ \\
\hline$>5$ & $29(22 \%)$ & $98(18 \%)$ & $16(7 \%)$ & $10(11 \%)$ & $1(5 \%)$ \\
\hline
\end{tabular}

Statistical analysis were done using SPSS version 21. Variables are presented as absolute frequency. The ANOVA for continuous variables and the chi-squared test for categorical variables were used to compare various groups. A $p$-value $\leq 0.05$ were considered statistically significant. Logistic regression was used to adjust potential confounders. The complications risks of pregnancy wereexpressed as adjusted odd ratio with 95\% confidence intervals.

\section{RESULTS}

This study included 1000 women whose complete information was present. Out of these 1000, $130(13 \%)$ were underweight, $540(54 \%)$ belonged to normal BMI, while $220(22 \%), 90(9 \%)$ and $20(2 \%)$ women were from the overweight, obese and the morbidly obese categories respectively. The selected demographic characteristics of the women have been categorizedinto five groups according to their BMI as shown in table-I.
The labour induction risk is lower in underweight women $\{$ OR 0.8 (95\% CI $0.55,1.35)\}$ and high in the morbidly obese $\{\mathrm{OR}$ of 2.7 (95\% CI 1.1, 6.8)\}, showed the frequency of induction increased with increasing BMI. With increasing BMI, the occurrence of cesarean section either elective or emergency raised, in the overweight and obese group. The frequency of instrumental delivery was found more in overweight and obese group with OR $3.5(95 \% \mathrm{CI} 1.1,11.2)$ and $2.4(95 \%$ CI $0.4,12.7)$. The risk of postpartum hemorrhage was found in extreme of BMI group with risk in underweight group is 1.92 (95\% CI 0.6-5.6) and morbidly obese category is 2.5 (95\% CI 0.31-20.6). The increasing trend of anemia was found in underweight group with adjusted relative risk 2.47 (95\% CI 1.6-3.6). The risk of $\mathrm{PPH}$ in underweight seems to be due to anemia. Large for gestational age was seen more in morbidly obese with linear rise in frequency as weight increasing. As 
compared to standard BMI, underweight category has more frequent small for gestational age with Odds Ratios of 4.6 (95\% CI 2.6, 8.1).
The link between induced labour and ceasearean section with abnormal BMI was shown by many previous studies ${ }^{12,13}$ and our study also agreed with this

Table-II: The frequency of obstetrics complications in body mass index group.

\begin{tabular}{l|c|c|c|c|c|c}
\hline Pregnancy Complications & $\begin{array}{c}\text { Under } \\
\text { Weight }\end{array}$ & $\begin{array}{c}\text { Normal } \\
\text { Weight }\end{array}$ & Overweight & Obesity & $\begin{array}{c}\text { Mobidly } \\
\text { Obese }\end{array}$ & $p$-value \\
\hline Anaemia & $73(56 \%)$ & $184(34 \%)$ & $37(17 \%)$ & $11(12 \%)$ & $01(7 \%)$ & 0.002 \\
\hline Gestational Diabeties Mellitius & $01(1 \%)$ & $22(4 \%)$ & $11(5 \%)$ & $09(10 \%)$ & $06(30 \%)$ & $<0.005$ \\
\hline Preeclampsia & $04(3 \%)$ & $49(9 \%)$ & $24(11 \%)$ & $12(13 \%)$ & $07(32 \%)$ & 0.001 \\
\hline Large for Gestational Age & $01(0.8 \%)$ & $12(2 \%)$ & $18(8 \%)$ & $12(13 \%)$ & $4(21 \%)$ & $<0.005$ \\
\hline Small for Gestational Age & $27(20.7 \%)$ & $29(5 \%)$ & $15(7 \%)$ & $5(6 \%)$ & $11(7 \%)$ & $<0.005$ \\
\hline Postpartum Hemorrhage & $05(4 \%)$ & $11(2 \%)$ & $02(1 \%)$ & $02(2.2 \%)$ & $01(5 \%)$ & 0.36 \\
\hline Spontaneous Vaginal Delivery & $113(87 \%)$ & $443(82 \%)$ & $158(72 \%)$ & $54(5.3 \%)$ & $6(30 \%)$ & $<0.005$ \\
\hline Induced labour & $31(24 \%)$ & $145(27 \%)$ & $72(33 \%)$ & $38(42 \%)$ & $10(50 \%)$ & 0.003 \\
\hline Ceasarian Section & $10(8 \%)$ & $42(7.7 \%)$ & $25(11.4 \%)$ & $24(26.6 \%)$ & $7(35 \%)$ & $<0.005$ \\
\hline Emergency Ceasarian section & $6(4.6 \%)$ & $50(9.2 \%)$ & $30(13.6 \%)$ & $10(11.1 \%)$ & $7(35 \%)$ & $<0.005$ \\
\hline Elective Ceasarian section & $1(0.8 \%)$ & $5(0.92 \%)$ & $07(3 \%)$ & $02(2.2 \%)$ & 0 & 0.16 \\
\hline Instrumental delivery
\end{tabular}

Table-III: Adjusted odds ratio of pregnancy complications in the abnormal body mass index groups compared to normal body mass index group.

\begin{tabular}{l|c|c|c|c}
\hline Pregnancy Complication & Underweight & Overweight & Obese & Mobidly Obese \\
\hline Anaemia & $2.47(1.6,3.6)$ & $0.3(0.26,0.58)$ & $0.256(0.14,0.510$ & $0.10(0.14,0.76)$ \\
\hline Gestational Diabetis Mellitus & $0.18(0.02,1.3)$ & $1.23(0.59,2.6)$ & $2.6(1.16,5.8)$ & $10.0(3.5,28.7)$ \\
\hline Preeclampsia & $0.31(0.11,0.89)$ & $1.27(0.73,2.05)$ & $1.54(0.78,3.02)$ & $5.3(2.0,14.1)$ \\
\hline Large for Gestational Age & $0.34(0.04,2.6)$ & $3.9(1.8,8.2)$ & $6.7(2.9,15.5)$ & $11.0(3.1,37.8)$ \\
\hline Small for gestational age & $4.6(2.6,8.1)$ & $1.28(0.67,2.4)$ & $1.03(0.39,2.75)$ & $21.5(8.2,56.0)$ \\
\hline Postpartum Hemorrhage & $1.92(0.6,5.6)$ & $0.44(0.097-2.00)$ & $1.09(0.23,5.0)$ & $2.5(0.31,20.6)$ \\
\hline Spontaneous Vaginal Delivery & $1.31(0.75,2.2)$ & $0.50(0.3,0.7)$ & $0.28(0.17,0.45)$ & $0.19(0.08,0.48)$ \\
\hline Induced labor & $0.86(0.55,1.35)$ & $1.35(0.96,1.8)$ & $2.0(1.28,3.21)$ & $2.7(1.1,6.8)$ \\
\hline Ceasarian Section & $0.47(0.19,1.13)$ & $1.63(1.0,2.6)$ & $1.63(0.78,3.4)$ & $6.9(2.4,19.5)$ \\
\hline Emergency Ceasarian section & $0.96(0.46,1.9)$ & $1.65(0.97,2.8)$ & $4.9(2.8,8.8)$ & $4.8(1.4,16.4)$ \\
\hline Elective Ceasarian section & $0.82(0.96-7.16)$ & $3.5(1.1-11.2)$ & $2.4(0.4-12.7)$ & 0 \\
\hline Instrumental delivery
\end{tabular}

\section{DISCUSSION}

This study suggests that not only the high body mass index, low BMI also predisposes women to adverse pregnancy outcomes.Our study has shown a linear relationship of having pre-eclampsia, gestational diabetes, and risk of emergency caesarean section with obesity (high BMI).

Obesity is a risk factor for development of gestational hypertension and gestational diabetes as indicated by logistic regression analysis in this study. Similar association of increased BMI with development of hypertension and hyperglycemia had been observed in various studies 9,10 . A meta analysis ${ }^{11}$ emphasized that with each $5-7 \mathrm{~kg} / \mathrm{m}^{2}$ increase in BMI, the risk of pregnancy induced hypertension magnified. We analysed the risk of pre-eclampsia 3 and 7 times higher in obese and morbidly obese women respectively, whereas underweight women havea remarkably lower risk of preeclampsia \{OR 0.31(95\% CI 1.11-0.89)\}. association. The obesity increased the risk of emergency ceasarean section whereas the rate of spontanoes labour is low with increased BMI. The increased BMI carried high risk of perioperative morbidity like anaesthetic problems, infections and prolonged hospitalization. The risk of postpartum hemorrhage is more with obese women in our study which was similar with the studies of Butwick ${ }^{14}$. According to this cohort study overweight and obese women had up to $19 \%$ increased risk of hemorrhage. The risk of anemia increased with underweight BMI as expressed by cohort study od Indonesia ${ }^{15}$, which is similar with our study.

We found strong relationship between BMI and fetal weight. The risk of small for gestational age was higher in underweight group, while the large for gestational age (macrosomia birth weight more than $4.5 \mathrm{~kg}$ ) was greater in the BMI above 30 . The association of maternal obesity with fetal growth has been established by many studies ${ }^{16,17}$ and they expressed that 18- 
$26 \%$ increased risk of having an infants with macromic baby without gestational diabetes ${ }^{18}$.

The strength of our study is that it is single centre study with women belonging to multiethnic and varied socio-economic strata. Being the single centre study cutdown the effects of variation in clinical practice and its effects on outcome. This study has several limitations like any other observational study. Prepregnancy BMI should be ideal for evaluation is one of the limitations. In our study we included all those women who registered before 16 weeks inorder to minimize the effects of gestational weight gain. The other limitation of this study was its retrospective nature, due to which some of the socio-demographic details such as level of education, socio-economic status could not be assessed.

\section{CONCLUSION}

The present study suggests that half of the women embark on pregnancy with abnormal BMI. Women having abnormal weight are at risk of pregnancy complication which includes preeclampsia, gestational diabetes, caesarean section rate, labor induction and macrosomic babies with obesity while anemia and small for getational age for underweight BMI. So emphasis should be given to pre pregnancy weight reduction, nutritional education and life style modification to improve pregnancy outcomes.

\section{CONFLICT OF INTEREST}

This study has no conflict of interest to be declared by any author.

\section{REFERENCES}

1. GBD 2015 Obesity Collaborators. Health effects of overweight and obesity in 195 countries over 25 years. New Engl J Med 2017; 377(1): 13-27.

2. Abarca-Gómez L, Abdeen ZA, Hamid ZA, Abu-Rmeileh NM, Acosta-Cazares B, Acuin C, et al. Worldwide trends in bodymass index, underweight, overweight, and obesity from 1975 to 2016: a pooled analysis of 2416 population-based measurement studies in 128.9 million children, adolescents, and adults. Lancet 2017; 390(10113): 2627-42.

3. Short VL, Geller SE, Moore JL, McClure EM, Goudar SS, Dhaded $\mathrm{SM}$, et al. The relationship between body mass index in pregnancy and adverse maternal, perinatal, and neonatal outcomes in Rural India and Pakistan. Am J Perinatol 2018; 35(9): 844.

4. Siddiqui M, Hameed R, Nadeem M, Mohammad T, Simbak N,
Latif AZ, et al. Obesity in Pakistan; current and future perceptions. J Curr Trends Biomed Eng Biosci 2018; 17: 1-4.

5. Pan Y, Zhang S, Wang Q, Shen H, Zhang Y, Li Y, et al. Investigating the association between prepregnancy body mass index and adverse pregnancy outcomes: a large cohort study of 536098 Chinese pregnant women in rural China. Br Med J open 2016; 6(7): e011227.

6. Hung TH. Pregestational body mass index, gestational weight gain, and risks for adverse pregnancy outcomes among Taiwanese women: a retrospective cohort study. Taiwanese J Obs Gyne 2016; 55(4): 575-81.

7. Patel A, Prakash AA, Das PK, Gupta S, Pusdekar YV, Hibberd PL. Maternal anemia and underweight as determinants of pregnancy outcomes: cohort study in eastern rural Maharashtra, India. Br Med J open 2018; 8(8): e021623.

8. World Health Organization. Geneva: WHO; 2000. The Asia Pacific Perspective- Redefining Obesity and Its treatment.

9. Soltani H, Lipoeto NI, Fair FJ, Kilner K, Yusrawati Y. Pre-pregnancy body mass index and gestational weight gain and their effects on pregnancy and birth outcomes: a cohort study in West Sumatra, Indonesia. BMC women's health 2017; 17(1): 102.

10. Vernini JM, Moreli JB, Magalhães CG, Costa RA, Rudge MV, Calderon IM. Maternal and fetal outcomes in pregnancies complicated by overweight and obesity. Reproductive Health 2016; 13(1): 100 .

11. Poorolajal J, Jenabi E. The association between body mass index and preeclampsia: a meta-analysis. J Maternal-Fetal Neonatal Med 2016; 29(22): 3670-76.

12. Xiong C. Association of pre-pregnancy body mass index, gestational weight gain with cesarean section in term deliveries of China. Sci Rep 2016; 6(1): 1-6.

13. Xiong C, Zhou A, Cao Z, Zhang Y, Qiu L. Association of prepregnancy body mass index, gestational weight gain with cesarean section in term deliveries of China. Sci Rep 2016; 6(1): 1-6.

14. Carlhäll S, Källén K, Blomberg M. The effect of maternal body mass index on duration of induced labor. Acta Obstet Gynecol Scand 2020; 99(5): 669-78.

15. Butwick AJ, Abreo A, Bateman BT, Lee HC, El-Sayed YY, Stephansson $\mathrm{O}$, etal. Effect of maternal body mass index on postpartum hemorrhage. J Am Soc Anesthesiol 2018; 128(4): 774-83.

16. Mocking M, Savitri AI, Uiterwaal CS, Amelia D, Antwi E, Baharuddin $\mathrm{M}$, et al. Does body mass index early in pregnancy influence the risk of maternal anaemia? An observational study in Indonesian and Ghanaian women. BMC Pub Health 2018; 18(1): 873.

17. Zhang B, Yang S, Yang R, Wang J, Liang S, Hu R, et al. Maternal Prepregnancy body mass index and small for gestational age births in Chinese women. Paed Perinatal Epidemiol 2016; 30(6): 550-54.

18. Dai RX, He XJ, Hu CL. Maternal pre-pregnancy obesity and the risk of macrosomia: a meta-analysis. Arch Gynecol Obstet 2018; 297(1): 139-45.

19. Gaudet L, Ferraro ZM, Wen SW, Walker M. Maternal obesity and occurrence of fetal macrosomia: a systematic review and metaanalysis. Bio Med Res Intl 2014; 2014: 1-6. 